\title{
Personal exposure monitoring of particulate matter, nitrogen dioxide, and carbon monoxide, including susceptible groups
}

\author{
R M Harrison, C A Thornton, R G Lawrence, D Mark, R P Kinnersley, J G Ayres
}

See end of article for authors' affiliations

Correspondence to:
Prof. R M Harrison,
Division of Environmental
Health \& Risk
Management, University of
Birmingham, Edgbaston,
Birmingham B15 2TT, UK;
R.M.Harrison.ipe@
bham.ac.uk
Accepted
13 February 2002

\begin{abstract}
Aims: To investigate the relation between personal exposures to nitrogen dioxide, carbon monoxide, and $\mathrm{PM}_{10}$, and exposures estimated from static concentrations of these pollutants measured within the same microenvironments, for healthy individuals and members of susceptible groups.

Methods: Eleven healthy adult subjects and 18 members of groups more susceptible to adverse health changes in response to a given level of exposure to nitrogen dioxide, carbon monoxide, and/or $\mathrm{PM}_{10}$ than the general population (six schoolchildren, six elderly subjects, and six with pre-existing diseasetwo with chronic obstructive pulmonary disease (COPD), two with left ventricular failure (LVF), and two with severe asthma) were recruited. Daytime personal exposures were determined either directly or through shadowing. Relations between personal exposures and simultaneously measured microenvironment concentrations were examined.

Results: Correlations between personal exposures and microenvironment concentration were frequently weak for individual subjects because of the small range in measured concentrations. However, when all subjects were pooled, excellent relations between measured personal exposure and microenvironment concentration were found for both carbon monoxide and nitrogen dioxide, with slopes of close to one and near zero intercepts. For $\mathrm{PM}_{10}$, a good correlation was also found with an intercept of personal exposure (personal cloud) of 16.7 (SD 10.4) $\mathrm{\mu g} / \mathrm{m}^{3}$. Modelled and measured personal exposures were generally in reasonably good agreement, but modelling with generic mean microenvironment data was unable to represent the full range of measured concentrations.

Conclusions: Microenvironment measurements of carbon monoxide and nitrogen dioxide can well represent the personal exposures of individuals within that microenvironment. The same is true for $\mathrm{PM}_{10}$ with the addition of a personal cloud increment. Elderly subjects and those with pre-existing disease received generally lower $\mathrm{PM}_{10}$ exposures than the healthy adult subjects and schoolchildren by virtue of their less active lifestyles.
\end{abstract}

ti $\mathrm{n}$ recent decades, air quality and the exposure of populations to airborne pollutants has received much attention. This interest has focused on outdoor air quality, with the majority of air quality monitoring stations located out of doors. There is, however, a strong awareness that the contribution of indoor air quality to the exposure of an individual to pollutants is of importance. ${ }^{1}$ This is especially significant from a public health perspective as individuals spend an estimated $70-90 \%$ of their time indoors. ${ }^{2-5}$ The determination of an individual's exposure to air pollution is dependent on the individual and his/her activity patterns, which is reflected in the time spent in different microenvironments. ${ }^{4}$ It has been estimated that of the time spent indoors, the home contributes approximately $60 \%$, which suggests that significant exposures may occur in the home. This is of particular importance to individuals who are elderly or have existing illness and are likely to spend the majority of their time in the home.

In addition to the home, other indoor microenvironments, and particularly the workplace, are important determinants of overall personal exposure. In an earlier study of personal exposure to monoaromatic hydrocarbons such as benzene and toluene, we have shown that for four exposed groups (homemakers, office workers, the elderly, and students), modelled personal exposures constructed from microenvironment concentrations and personal activity diaries can provide a good prediction of overall measured personal exposure. ${ }^{7}$ There is, however, recognition in the literature that for particulate matter, measured personal exposures generally exceed concentra- tions measured within the same microenvironments, and this has led to postulation of a "personal cloud" effect. ${ }^{8}$ For pollutants other than particles, there is a far less complete knowledge of the relation between modelled and measured personal exposures.

Certain groups within the population show greater adverse health responses following exposure to a given level of one or more of the three pollutants in this study than seen in the general population. It is important to assess whether such susceptible groups, which include children, the elderly, or those with certain respiratory or cardiovascular illness, have a notably different exposure pattern from the general population as a consequence of differences in activity pattern. It is also important to determine whether fixed point monitors represent their exposures any better or worse than those of the population as a whole. Members of such groups have therefore been included within this study.

We therefore set out to answer two specific questions that have a significant bearing on our ability to produce reliable estimates of personal exposure to common airborne pollutants:

Abbreviations: COPD, chronic obstructive pulmonary disease; ETS, environmental tobacco smoke; LVF, left ventricular failure; PM, particulate matter 
(1) Does modelling through the use of microenvironment measurements and activity diaries produce reliable estimates of personal exposure to air pollutants?

(2) Do differences in activity patterns between the population as a whole and susceptible groups affect the latter's exposure to air pollutants in such a way that estimates of exposure based on the population as a whole are unrepresentative of exposures received by susceptible groups?

The pollutants selected for study were nitrogen dioxide $\left(\mathrm{NO}_{2}\right)$, carbon monoxide $(\mathrm{CO})$, and particulate matter less than $10 \mu \mathrm{m}$ in aerodynamic diameter $\left(\mathrm{PM}_{10}\right)$. The rationale for selecting these pollutants was as follows:

- Carbon monoxide is of low chemical reactivity and hence inert in the context of residence times in the indoor atmosphere. Its sources are well defined. It can be measured accurately by instrumental means and it therefore represents an ideal unreactive tracer testing the basic methodology of exposure measurement and modelling adopted. Carbon monoxide is a product of incomplete combustion, with motor vehicles the dominant outdoor source. In the home, levels can be affected by the presence of gas cookers and some heating systems. In addition to these, indoor levels can be affected by environmental tobacco smoke (ETS), ingress of exhaust fumes from an attached garage, and proximity to heavily trafficked roads. ${ }^{4}$ As $\mathrm{CO}$ is an unreactive gas the usual route of removal is via ventilation. Its adverse health effects at levels typically encountered indoors and at the roadside are well documented, and include significant reduction of exercise duration because of exacerbation of cardiovascular symptoms in individuals with reproducible exercise induced ischaemia."

- Nitrogen dioxide is far more reactive than carbon monoxide. It is believed to be of public health significance, with a WHO long term exposure guidance value given on the basis of epidemiological evidence for an association of exposure with increased respiratory illness in children. ${ }^{10}$ Nitrogen dioxide can be both formed and removed chemically in the indoor atmosphere and may therefore show greater spatial variability than carbon monoxide, with a greater potential for discrepancies between personal and static concentration measurements. Nitrogen oxides are produced by all combustion processes, and indoor concentrations of $\mathrm{NO}_{2}$ are known to be influenced by outdoor levels. ${ }^{11}$ However, the principal sources in the home are gas cookers, gas water heaters, and unvented space heating, where present. Car fumes entering the home via attached garages, and ETS can also contribute to indoor $\mathrm{NO}_{2}$ concentrations to a lesser extent. ${ }^{12}$ The removal of $\mathrm{NO}_{2}$ from the indoor environment takes place via ventilation and reaction with indoor surfaces.

- $P M_{10}$ is currently of great interest because of its public health significance. Its behaviour is also likely to be more complex than that of the gas phase pollutants, as it has several indoor sinks and sources, with indications in the literature of a "personal cloud" effect related to localised generation of $\mathrm{PM}_{10}$ particles as a consequence of human activity, such that the convective plume around the body of an individual carries dust originating from the body and clothing and from resuspension arising as a consequence of the activity of the person. ${ }^{4}$ Particles in indoor air can arise from both indoor and outdoor sources. ${ }^{13}$ ETS has been shown to be a significant source of indoor particles, ${ }^{4}$ as are cooking, both from the heating of the food itself and the combustion of the cooking fuel, ${ }^{14}$ and residue from personal care and cleaning products, pesticides, pollen, spores, bacteria, dust mite detritus, and viruses. ${ }^{45}$ Indoor particle levels can also be influenced by such activities as sweeping, dusting, and vacuuming. ${ }^{4}$ Activity acts as a secondary source, resuspending particles that have settled on surfaces, and can be a key factor in determining personal exposure to particulate matter. Personal levels have been found to be higher than corresponding indoor static concentrations ${ }^{14}$ because of the previously mentioned "personal cloud" effect. In addition to this effect, volunteers wearing the personal sampling equipment may be closer to sources, for example, while they are cooking.

\section{EXPERIMENTAL METHODS}

\section{Study design}

The study involved an initial period of method development and validation. This was followed by two main investigative phases:

- Phase 1: Establishment of the relations between the direct and indirect methods of measuring pollutant exposures. Using a number of volunteer subjects, personal exposure was measured directly through attaching personal samplers to the subjects and estimated indirectly through a combination of microenvironment measurements and activity diaries indicating the periods of time spent by the various subjects in the different microenvironments.

Healthy adult volunteers were recruited for this section of the study. They were requested to go about their everyday life while wearing personal sampling equipment. In addition to this, static equipment was sited in the volunteer's home, in the room most frequently used during waking hours. This was generally a living room, and in the majority of cases was in close proximity to the kitchen.

Eleven volunteers were recruited to undertake this section of the work. They were required to carry out the sampling for 10 day periods and thus incorporated weekend sampling where possible. Sampling was carried out for approximately eight hours per day.

- Phase 2: Investigation of the difference of exposure patterns between susceptible groups of the population and healthy groups. Small panels of susceptible individuals were set up and their exposures estimated through personal sampling of an investigator who shadowed the activity of the susceptible group members. Additionally, microenvironment methods were operated within the homes (and school) of the susceptible groups. The range of exposures within the susceptible groups were compared with those of the healthy volunteers used in phase 1 .

Three susceptible subgroups were identified. These were the young, the elderly, and those with existing illness known to increase susceptibility to the adverse effects of air pollutants. People were chosen from within these groups, and their daily lives were shadowed by a researcher wearing the personal sampling equipment as it was not considered appropriate to have them wearing the bulky equipment themselves.

Shadowing was carried out with six children, six elderly people, and six people with existing illness (two with chronic obstructive pulmonary disease (COPD), two with left ventricular (heart) failure (LVF), and two with severe asthma). This was done for six hours a day, for five day periods (Monday to Friday).

The study of the young persons group was carried out in a Year 6 class (approximately 10 years of age) at a primary school in Birmingham. Six children were shadowed during their school day. To do this, slight adjustments to sampling times were made to fit in with the school timetable. Static $\mathrm{NO}_{2}$ and $\mathrm{PM}_{10}$ measurements were made in the classroom. Static CO measurements were also made, but because of the noise and size of the CO analyser these measurements had to be made in a separate classroom.

Six elderly subjects (aged >65 years) were shadowed during their normal day. In most cases the majority of time was spent in the home, with some time spent at local shops or 
Table 1 Description of sites monitored as part of microenvironment sampling

\begin{tabular}{ll}
\hline Site & Description \\
\hline Pub & $\begin{array}{l}\text { Student Union bar on Birmingham University } \\
\text { Campus, Selly Oak } \\
\text { Busy café sited in Selly Oak, Birmingham (using } \\
\text { both electric and gas stoves) } \\
\text { Gift shop situated adjacent to A38 (very heavily } \\
\text { trafficked road) in Selly Oak, Birmingham } \\
\text { Shop }\end{array}$ \\
Urban park in a residential area situated at Fox \\
Hollies, Birmingham
\end{tabular}

walking dogs. Static equipment was sited within the home, again in the most frequently used room. Staff at Birmingham Heartlands Hospital recruited the six volunteers with severe disease. Many of these subjects spent much time in their home, although one subject worked full time, and in this case, the shadowing was carried out in the place of work. Static site monitors were placed either in the home or the place of work depending on where the majority of sampling time was spent.

Additional microenvironment measurements

In addition to home and work place, microenvironments that were identified through activity diaries as relevant to the volunteers were leisure locations (social clubs, pubs, and cafés), transport (cars, buses, and trains), shops, and park area (dog walking). Representative locations were identified with the objective of collecting between 10 and 15 hours of simultaneous static and personal exposure at each site. Table 1 describes the sites in more detail. Static $\mathrm{PM}_{10}$ measurements were not possible in the shop and train microenvironments.

\section{Sampling methodology \\ $\mathrm{NO}_{2}$}

A method ${ }^{16}$ was developed in our laboratories specifically for use in this project, and involved drawing air through Sep-Pak $\mathrm{C}_{18}$ cartridges impregnated with triethanolamine. The same method was used for both personal and static monitoring, with samples collected over one hour averaging periods. In the earlier part of the work, static concentrations were measured with a Scintrex LMA-3 luminol chemiluminescent continuous analyser (Unisearch, Canada), calibrated with standard $\mathrm{NO}_{2}$ in nitrogen gas mixtures.

\section{Carbon monoxide}

A TECO model 48C infrared spectrophotometer was deployed to measure static carbon monoxide continuously.

For personal carbon monoxide monitoring, air was pumped with a personal sampling pump at a constant rate of 75 $\mathrm{ml} / \mathrm{min}$ for one hour periods into $5 \mathrm{l}$ gas bags, after removal of particles using a PTFE filter. The bags were worn around the waist with inlets collecting air from the breathing zone. After collection, the air was analysed with the TECO model 48C analyser, providing an average CO concentration for the hour's sampling.

\section{$\mathrm{PM}_{10}$}

A Grimm model 1.106 dust monitor was used for static $\mathrm{PM}_{10}$ measurements. This is an optical instrument, but intercomparison with a TEOM gravimetric instrument has shown good agreement for particle mass in the indoor atmosphere. ${ }^{14}$

Personal exposure to $\mathrm{PM}_{10}$ was measured with a personal foam thoracic sampler. ${ }^{17}$ This is worn in the breathing zone, and samples air at $2 \mathrm{l} / \mathrm{min}$ onto a PTFE filter; size selection for $\mathrm{PM}_{10}$ is achieved by means of a polyurethane foam plug at the inlet. Sampling extended for periods of 20-28 hours in order to collect a sufficient mass of particles for accurate weighing. The filters were weighed in a temperature and humidity controlled environment to determine a mass concentration. This technique has also been shown to give good agreement with a TEOM gravimetric instrument when operated statically alongside. $^{14}$

\section{Modelling of personal exposure}

Carrying out direct personal exposure measurements is costly and time consuming. For this reason, it is important to find other methods of assessing accurately an individual's exposure to pollutants. This can be done in a number of different ways and for the purpose of this study, modelled 5 hour and 24 hour integrated personal exposures were calculated for the susceptible groups (the young, the elderly, and those with existing illness) using the microenvironment measurements and activity patterns collected as a part of this study.

These were calculated from the equation:

5 or 24 hour integrated personal exposure

$(\mathrm{ppb} . \mathrm{h})=\sum_{0}^{n} \mathrm{C}_{x} t_{x}$

where $\mathrm{C}_{x}=$ mean concentration in microenvironment $x(\mathrm{ppb})$; and $t_{x}=$ time spent in microenvironment $x(\mathrm{~h})$.

\section{RESULTS}

\section{Static monitoring data (phase 1)}

In the case of both nitrogen dioxide and carbon monoxide, the mean and range of concentrations were fairly typical of background urban air, representing the ingress of polluted outdoor air into buildings with some additional modification because of indoor sources. In the case of $\mathrm{PM}_{10}$, however, the vast majority of the concentrations greatly exceeded those measured at urban background locations, implying emissions of particulate matter from indoor sources.

\section{Personal monitoring results (phase 1)}

For $\mathrm{NO}_{2}$ and $\mathrm{CO}$, hourly integrated personal exposure data were collected, and from activity diaries filled out during the sampling period it was possible to assign to each data point contributions from the different microenvironments in which the volunteer had spent time. Increases in concentration were observed associated with travel in a car, proximity to roads and, for $\mathrm{CO}$, proximity to a bonfire. The exact contribution from these sources cannot be calculated, as frequently volunteers will not spend the entire one hour sampling period in the same microenvironment. Personal $\mathrm{PM}_{10}$ data were collected over $2-3$ day periods, providing an average mass concentration for this period. For this reason it is not possible to identify elevations associated with individual sources or activities.

Table 2 shows a summary of all the personal data collected as part of the exposure study. Average concentrations shown for $\mathrm{NO}_{2}$ and $\mathrm{CO}$ were calculated from one hour samples over the entire sampling period, while the $\mathrm{PM}_{10}$ data were from 2-3 day exposures.

\section{Comparison between personal and static concentrations (phase 1)}

Because of the nature of this phase of the work, it was not always possible to obtain directly comparable data as the healthy volunteers used in this phase of the study often spent much of their time away from home, while static data were collected only in the home. This, coupled with problems 
Table 2 Summary of personal exposure study results (phase 1)

\begin{tabular}{llcc}
\hline \multirow{2}{*}{ Volunteer } & \multicolumn{3}{l}{ Mean personal concentrations (SD) } \\
\cline { 2 - 4 } & $\mathrm{NO}_{2}(\mathrm{ppb})$ & $\mathrm{CO}(\mathrm{ppm})$ & $\mathrm{PM}_{10}\left(\mu \mathrm{g} / \mathrm{m}^{3}\right)$ \\
\hline 1 & $7.0(2.7)$ & $0.51(0.10)$ & 38.7 \\
2 & $26.0(17.6)$ & $0.47(0.40)$ & 68.1 \\
3 & $18.3(13.8)$ & $0.54(0.12)$ & 21.6 \\
4 & $6.0(3.7)$ & $0.57(0.26)$ & 107.0 \\
5 & $22.7(14.8)$ & $1.45(1.75)$ & 71.6 \\
6 & $19.0(8.9)$ & $0.64(0.20)$ & 7.2 \\
7 & $14.9(6.5)$ & $0.38(0.17)$ & 29.5 \\
8 & $33.5(63.2)$ & $0.41(0.19)$ & 16.3 \\
9 & $18.5(17.4)$ & $1.09(0.80)$ & 21.8 \\
10 & $1.1(1.7)$ & $0.73(0.45)$ & - \\
11 & $16.9(22.1)$ & $0.60(0.60)$ & 167.3 \\
Overall average & 16.7 & 0.67 & 54.9 \\
\hline
\end{tabular}

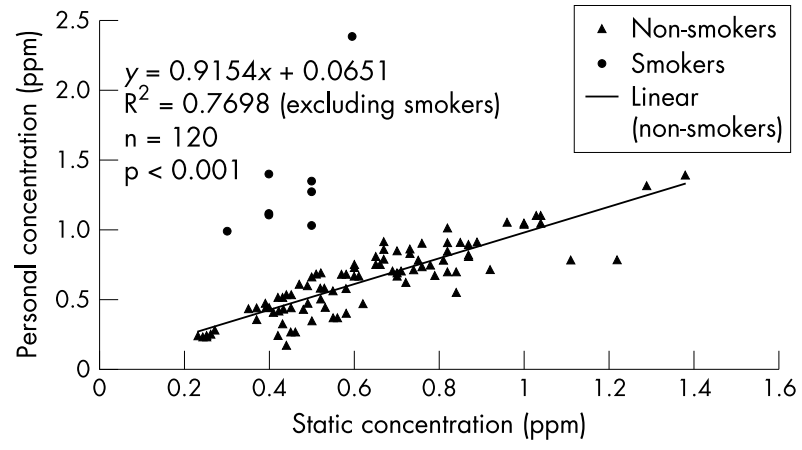

Figure 1 Plot of directly comparable personal and static carbon monoxide concentrations from the phase 1 exposure study.

encountered with the Scintrex analyser, means there are no directly comparable data available from this section of the work for $\mathrm{NO}_{2}$.

Figure 1 shows all the directly comparable data for CO. It can be seen that most of the data lies close to a trend line with a few outliers. When volunteer information is studied, these outliers can be clearly associated with environmental tobacco smoke (ETS). For non-smokers, a gradient approaching 1 is observed with a near zero intercept.

Table 2 shows averaged phase $1 \mathrm{PM}_{10}$ data for each volunteer. Comparable sets of personal and static $\mathrm{PM}_{10}$ data, specifically those from sampling periods when the volunteer has spent the majority of time in the home and hence in the same microenvironment as the static sampler, were analysed, excluding data for smokers (for whom a great increase in particle concentration about the person might reasonably be expected). A good relation was observed $\left(R^{2}=0.90\right)$, with a gradient of 1.28 and an intercept of personal exposure of 33 $\mu \mathrm{g} / \mathrm{m}^{3}(\mathrm{n}=9)$.

\section{Personal sampling data (phase 2)}

Table 3 gives a summary of the personal data acquired from the different microenvironments. Average concentrations shown for $\mathrm{NO}_{2}$ and $\mathrm{CO}$ were calculated from one hour samples over the entire sampling period. Average concentrations shown for $\mathrm{PM}_{10}$ were measured gravimetrically from one sample collected over the sampling period. Linear regression relations were calculated between static concentration and personal exposures for each of the different microenvironments.

\section{Results from shadowing of susceptible groups}

Table 4 presents the results of regression analyses between personal exposure $(y)$ and static concentration $(x)$ measurements. Because of problems with the Scintrex analyser, static $\mathrm{NO}_{2}$ data were collected for only three of the periods of shadowing.

Table 5 presents results from the shadowing of elderly subjects. Static data for nitrogen dioxide were collected both with the Scintrex continuous instrument and with static Sep-Pak cartridges. The latter are directly comparable with the method used for personal nitrogen dioxide monitoring and do not require the lengthy stabilisation periods which the Scintrex needed. The regression relations obtained solely using the Sep-Pak cartridges are therefore more credible.

Table 6 presents data for subjects with pre-existing illness. Regression relations for nitrogen dioxide were also omitted as these most probably reflect of inadequate instrument stabilisation rather than the true relation between static and personal sampling results. Data collection for carbon monoxide was only possible for two of the subjects. In both cases

Table 3 Summary of the personal data acquired from the different microenvironments

\begin{tabular}{lccc}
\hline \multirow{4}{*}{ Microenvironment } & \multicolumn{2}{c}{ Mean personal concentrations (SD) } \\
\cline { 2 - 4 } & $\mathrm{NO}_{2}(\mathrm{ppb})$ & $\mathrm{CO}(\mathrm{ppm})$ & $\mathrm{PM}_{10}\left(\mu \mathrm{g} / \mathrm{m}^{3}\right)$ \\
\hline Café & $13.97(3.17)$ & $1.36(0.17)$ & 51.1 \\
Shop & $17.07(8.81)$ & $2.01(0.26)$ & 103.4 \\
Bar & $4.46(2.06)$ & $1.16(0.08)$ & 52.6 \\
Park & - & $1.12(0.47)$ & 42.0 \\
Workplace & $9.53(6.41)$ & $0.97(0.21)$ & 45.6 \\
Car & $13.12(5.45)$ & $1.14(0.36)$ & - \\
Bus & $20.80(7.29)$ & $1.15(0.16)$ & 92.5 \\
Train & $8.60(5.17)$ & $0.59(0.08)$ & 145.1 \\
\hline \multirow{2}{*}{ No standard deviation available for PM } &
\end{tabular}


Table 4 Comparison between personal and static results for shadowing study (the young)

\begin{tabular}{lllll}
\hline & \multicolumn{2}{l}{ Linear regression $\left(\mathrm{R}^{2}\right)$} & & Static:personal ratio \\
\cline { 2 - 3 } Subject & $\mathrm{NO}_{2}$ (Scintrex) $(\mathrm{ppb})$ & $\mathrm{CO}(\mathrm{ppm})$ & & $\mathrm{PM}_{10}$ \\
\hline Child 1 & - & - & - \\
Child 2 & - & - & - \\
Child 3 & - & $y=0.39 x+0.21(0.20)$ & \\
Child 4 & $y=1.14 x+0.30(0.93)$ & $y=1.10 x-0.12(0.86)$ & & 1.47 \\
Child 5 & $y=0.86 x+4.79(0.50)$ & $y=1.04 x-0.05(0.95)$ & \\
Child 6 & $y=1.78 x+4.86(0.41)$ & $y=1.19 x-0.46(0.53)$ & & 0.93 \\
\hline
\end{tabular}

\begin{tabular}{llll}
$\begin{array}{l}\text { Table } 5 \\
\text { elderly) }\end{array}$ & Comparison between personal and static results for shadowing study (the \\
\hline & \multicolumn{2}{l}{ Linear regression $\left(\mathrm{R}^{2}\right)$} & \\
\cline { 2 - 4 } Subject & $\mathrm{NO}_{2}$ (Static Sep-Pak) $(\mathrm{ppb})$ & $\mathrm{CO}(\mathrm{ppm})$ & Static:personal ratio \\
\hline OAP 1 & - & - & $\mathrm{PM}_{10}$ \\
OAP 2 & $y=0.39 x+1.17(0.50)$ & $y=1.02 x-0.03(0.75)$ & $0.02^{*}$ \\
OAP 3 & $y=3.65 x-3.96(0.39)$ & $y=0.76 x+0.20(0.62)$ & $0.11^{*}$ \\
OAP 4 & - & - & $0.12^{*}$ \\
OAP 5 & $y=0.72 x+0.78(0.73)$ & $y=0.29 x+0.37(0.06)$ & 0.31 \\
OAP 6 & $y=0.95 x-0.14(0.70)$ & $y=0.31 x+0.43(0.04)$ & 0.15 \\
\hline
\end{tabular}

Table 6 Comparison between personal and static results for shadowing study (pre-existing illness patients)

\begin{tabular}{|c|c|c|}
\hline \multirow[b]{2}{*}{ Subject } & Linear regression $\left(R^{2}\right)$ & $\begin{array}{l}\text { Static: personal } \\
\text { ratio }\end{array}$ \\
\hline & $\mathrm{CO}$ (ppm) & $\mathrm{PM}_{10}$ \\
\hline COPD 1 & $y=0.92 x+0.04(0.84)$ & 0.30 \\
\hline COPD 2 & $y=0.76 x+0.21(0.72)$ & 1.68 \\
\hline LVF 1 & - & 0.17 \\
\hline LVF 2 & - & 0.33 \\
\hline Asthma 1 & - & 0.61 \\
\hline Asthma 2 & - & 0.14 \\
\hline
\end{tabular}

strong relations between static concentrations and personal exposure were found. For $\mathrm{PM}_{10}$ in all but one case, the personal exposure considerably exceeded the static measurement, typically by a factor of around 3 .

\section{Modelling of personal exposure}

Because of initial difficulties with the Scintrex instrument, data for nitrogen dioxide were not considered sufficiently reliable for this exercise. In the case of both $\mathrm{CO}$ and $\mathrm{PM}_{10}$, one concentration, based on the mean of measurements, was adopted for each microenvironment. The relation between personal $(y)$ and static $(x) \mathrm{PM}_{10}$ of $y=1.17 x+17$ was used to correct the average static concentrations in each microenvironment to an equivalent personal concentration. Five hour integrated personal exposures to $\mathrm{CO}$ and $\mathrm{PM}_{10}$ were calculated for the young, the elderly, those with severe asthma, COPD, and LVF, and the "healthy" group from phase l based on activity diaries kept by the subjects. Actual measurements of personal exposure for the different groups were then converted into concentration.hour units (see table 7).

Twenty four hour integrated personal exposures to $\mathrm{CO}$ and $\mathrm{PM}_{10}$ were calculated for the young, the elderly, and those with severe disease (as a group) based on activity diaries filled out by 10 volunteers from each of these groups. For the young, a whole class (30 pupils) filled in the diaries as it was thought that this was more representative than selecting individuals; from these diaries, 10 were selected from those that were filled out correctly. In addition, two of the pupils suffered from asthma and their diaries were analysed separately. Tables 8 and 9 give the results of this analysis.

\begin{tabular}{|c|c|c|c|c|}
\hline \multirow[b]{2}{*}{ Volunteer group } & \multicolumn{2}{|c|}{ CO (ppm.h) } & \multicolumn{2}{|c|}{$\mathrm{PM}_{10}\left(\mu \mathrm{g} / \mathrm{m}^{3} \cdot \mathrm{h}\right)$} \\
\hline & Measured & Modelled & Measured & Modelled \\
\hline Elderly & 3.0 & 4.0 & - & - \\
\hline Smoking home & - & - & 850 & 159 \\
\hline Non-smoking & - & - & 93 & 142 \\
\hline COPD & 3.3 & 3.6 & 206 & 139 \\
\hline LVF & - & 3.7 & 169 & 131 \\
\hline Asthma & 2.7 & 4.4 & 146 & 167 \\
\hline Children & 5.8 & 4.3 & 448 & 292 \\
\hline Healthy & 3.7 & 6.3 & 191 & 178 \\
\hline
\end{tabular}


Table 8 Calculated mean 24 hour integrated personal exposure (SD) for different groups for carbon monoxide

\begin{tabular}{lll}
\hline Group & $\begin{array}{l}\text { Weekday exposure } \\
\text { (ppm.h) }\end{array}$ & $\begin{array}{l}\text { Weekend day } \\
\text { exposure (ppm.h) }\end{array}$ \\
\hline Young & $19.7(3.2)$ & $20.8(5.0)$ \\
Young with asthma* & $24.9(1.8)$ & $23.4(11.0)$ \\
Elderly & $22.8(3.6)$ & $22.6(3.4)$ \\
Severe asthma & $24.2(8.9)$ & $22.6(9.1)$ \\
COPD & $21.2(5.5)$ & $19.9(4.6)$ \\
LVF & $24.2(8.1)$ & $24.1(10.9)$ \\
Healthy & $22.6(3.9)$ & $19.5(3.1)$ \\
\hline * Limited data set. & \\
\hline
\end{tabular}

Table 9 Calculated mean 24 hour integrated personal exposure (SD) for different groups for $\mathrm{PM}_{10}$

\begin{tabular}{lll}
\hline Group & $\begin{array}{l}\text { Weekday exposure } \\
\left(\mu \mathrm{g} / \mathrm{m}^{3} . \mathrm{h}\right)\end{array}$ & $\begin{array}{l}\text { Weekend day } \\
\text { exposure }\left(\mu \mathrm{g} / \mathrm{m}^{3} . \mathrm{h}\right)\end{array}$ \\
\hline Young & $828.3(18.9)$ & $661.7(25.4)$ \\
Young with asthma* & $838.8(8.6)$ & $730.9(45.9)$ \\
Elderly & $692.6(23.4)$ & $675.1(20.6)$ \\
Severe asthma & $645.0(114.5)$ & $636.2(117.8)$ \\
COPD & $673.4(59.5)$ & $695.3(83.9)$ \\
LVF & $690.0(36.8)$ & $680.7(42.5)$ \\
Healthy & $718.3(17.1)$ & $684.2(45.0)$ \\
\hline \multirow{2}{*}{ *Limited data set. } & \\
\hline
\end{tabular}

\section{DISCUSSION}

\section{Shadowing}

$\mathrm{NO}_{2}$ data for shadowed children showed variable but generally statistically significant relations between personal and static concentrations, although it was only in later measurements that the same method was used for both static and personal concentrations so that wholly reliable relations were derived. These data should therefore be looked on with some caution. The data for carbon monoxide should, however, be reliable, and it is encouraging that three of the four regressions indicate slopes quite close to 1 , and intercepts that are generally quite small in relation to the concentrations. This is strongly suggestive of carbon monoxide personal exposures closely parallelling static concentrations within the school. Turning to $\mathrm{PM}_{10}$, the comparison of personal and static results (table 4) shows that during two of the three periods for which data are available, the static concentration exceeded the personal concentration, which is unusual for comparisons of this type.

For the pensioners there were also mixed results. For two (OAP 5 and OAP 6), $\mathrm{NO}_{2}$ showed a high correlation coefficient and a slope close to 1 . The regressions for carbon monoxide on these two subjects were not good, while those for subjects OAP 2 and OAP 3 showed both a high correlation coefficient and slopes reasonably close to 1 . The divergence in the apparent behaviour of these pollutants is unexpected, but probably explained by a greater range of concentrations for $\mathrm{NO}_{2}$ than for $\mathrm{CO}$, allowing more effective regression. The results for $\mathrm{PM}_{10}$ show appreciably higher personal concentrations than static (table 5). The difference is most notable for subjects OAP 1, 3 , and 4 , who were either smokers or living with smokers. The presence of smokers caused a large increment in the personal exposure concentration (see table 5), but not the static concentration. It is possible that the siting of the static monitor within the home was not such as to reflect fully the influence of ETS, which was relatively localised. Because of the rather anomalous nature of the data for the ETS exposed subjects 1, 3, and 4, these data points have been omitted from subsequent pooled data analyses.

\section{Comparison between all personal and static measurements}

For the statistical analyses on single sets of data shown above, the data are frequently clustered within a narrow range of values, or of a limited sample size, providing unsatisfactory regression and $\mathrm{R}^{2}$ values. This section discusses comparisons between all comparable personal and static measurements made as part of this project. The increased sample number and range should improve the power of the regression analysis to identify relations.

\section{Carbon monoxide}

When all the carbon monoxide data were pooled, a clear trend appeared in the data, with a near one-to-one relation between static and personal concentration data. There were, however, some points lying well off this line. To determine whether these outliers belonged to specific subsets of data, the pooled data were replotted with individual subsets identified (fig 2); ETS affected samples were omitted as atypical of normal ambient exposures. The anomalous data fell into three distinct classes: those collected at the park, café, and bar. In the case of the park, the static data were taken from a Birmingham City Council mobile unit sited close to the park, but across a road. A possible explanation is that the park was downwind of the road and experiencing higher concentrations, which were reflected in increased personal exposure values relative to measured static concentrations. The café and bar data may well be indicative of static measurements being made in little occupied areas of the café and bar influenced by extraction systems, whereas the personal data were collected in the more heavily occupied areas and were more subject to smokers, etc. If the data from these three sources are removed from the comparison, the plot shown in fig 3 results. This shows an

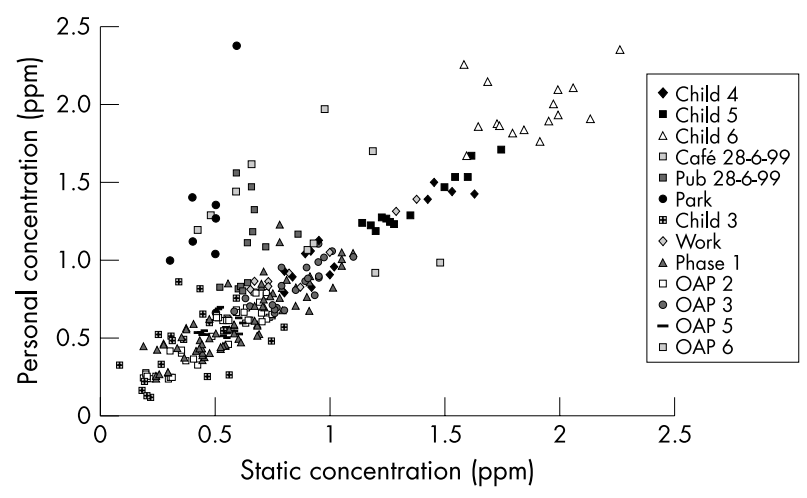

Figure 2 Plot of personal versus static carbon monoxide concentrations in terms of sampling location.

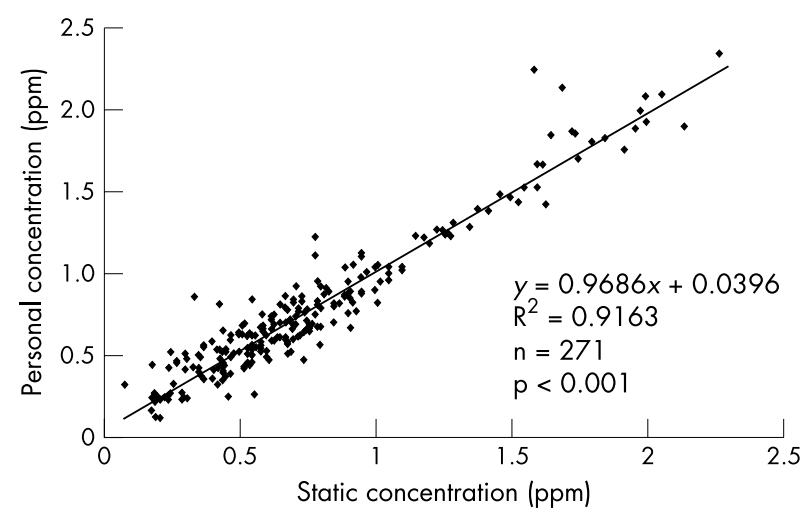

Figure 3 Plot of personal versus static carbon monoxide concentrations for phases 1 and 2, excluding data from the park, café, and bar, and samples affected by passive smoking. 


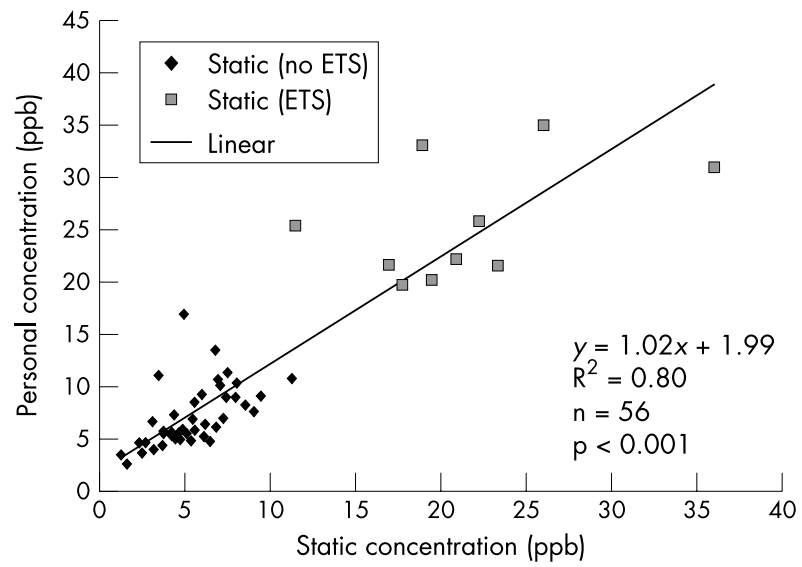

Figure 4 Plot of personal versus static concentrations of nitrogen dioxide measured by the Sep-Pak cartridge technique.

excellent relation between personal and static carbon monoxide relations with a very high regression coefficient, a slope of 0.97, and a near zero intercept. Clearly, in the case of carbon monoxide, personal exposures reflect microenvironment concentrations extremely well in many situations, the exceptions being identifiable circumstances that can result in high spatial variability within a microenvironment. Such circumstances include proximity of strong sources (notably ETS) and localised ventilation effects.

Carbon monoxide is perhaps the ideal analyte for this kind of study. It is chemically rather unreactive, and while spatial inhomogeneities arise as a result of local source emissions, concentrations within buildings are likely to be fairly uniform as a result of the absence of strong indoor sources and sinks, other than in the presence of smokers, gas fuelled domestic appliances, or localised ventilation. It is therefore unsurprising that after the removal of a small number of explainable outliers, the relation between measured personal exposure to carbon monoxide and the associated microenvironment concentration is excellent. This gives confidence that for carbon monoxide, measurement of microenvironment concentrations is generally an excellent predictor of personal exposure.

\section{Nitrogen dioxide}

Many of the early microenvironment concentration data in this study were invalid because of problems with the measurement instrument, which was very poorly suited to the rigours of frequent movement and switching on and off. However, the personal exposure measurement technique for nitrogen dioxide developed in the course of this study proved to be highly robust and gave excellent results. Data from samples collected using statically sited Sep-Pak cartridges were compared with personal measurements, as shown in fig 4. A strong relation was observed, with a gradient of 1.0 and a small intercept. The intercept ( $2 \mathrm{ppb}$ ) could possibly be related to exhalation of nitric oxide, which in some circumstances could be oxidised to nitrogen dioxide by ozone. This dataset, then, although smaller than that for carbon monoxide, confirmed a very close relation between personal exposure and the associated microenvironment concentration for nitrogen dioxide. Again, this gives confidence that measurements of microenvironment concentration are an excellent surrogate for personal exposure estimation in that microenvironment.

$\mathrm{PM}_{10}$

When collecting personal samples of $\mathrm{PM}_{10}$ gravimetrically, it is difficult to build up a large comparable data set because of the long sampling periods associated with the personal method. A data set sufficient for statistically meaningful analysis was

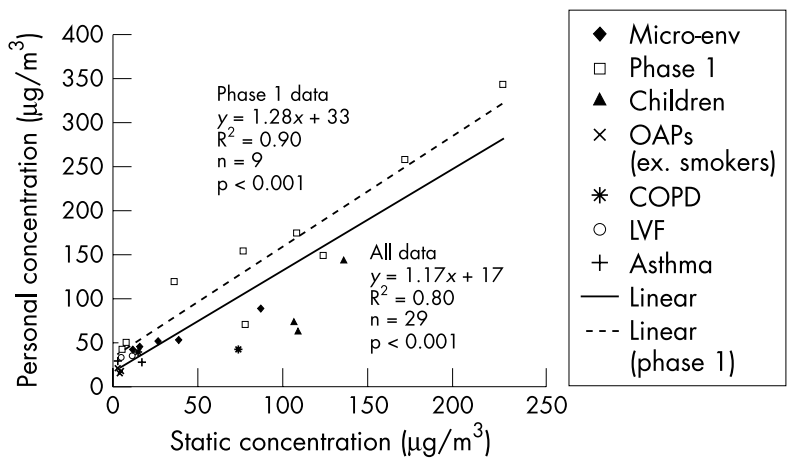

Figure 5 Plot of personal versus static concentrations for $\mathrm{PM}_{10}$.

acquired, however, and this is plotted in fig 5. For all pooled data a gradient of 1.17 was observed, with an intercept $( \pm 1$ SD) of $17(10) \mu \mathrm{g} / \mathrm{m}^{3}$. This intercept is lower than has been observed in a previous project involving healthy adults ${ }^{14}$ where an intercept of approximately $30 \mu \mathrm{g} / \mathrm{m}^{3}$ was found, and considerably smaller than that determined in the American PTEAM and THEES studies for $\mathrm{PM}_{10}{ }^{18}{ }^{19}$ However, when the data from the healthy adult volunteers in phase 1 are analysed alone, a line of intercept $33 \mu \mathrm{g} / \mathrm{m}^{3}$ and slope 1.28 is obtained, comparable to the value from the previous study, and suggesting that the personal cloud associated with the susceptible groups in this study is typically lower than that of healthy adults.

In a study conducted in the Netherlands, the median intercept in the relation between personal $\mathrm{PM}_{10}$ and indoor $\mathrm{PM}_{10}$ measurements was $13.1 \mu \mathrm{g} / \mathrm{m}^{3}$ with a median slope of 1.00 in measurements on 50-70 year old adults after excluding days with exposure to ETS. ${ }^{20}$ Here, too, the presence of less active elderly individuals may account for the reduced personal cloud. Most other studies of personal exposure to particles (for example, Lachenmyer and Hidy ${ }^{21}$ and Williams and colleagues ${ }^{22}$ ) have used particle size fractions smaller than $\mathrm{PM}_{10}$ and are therefore not directly comparable with this study. It can be seen from fig 5 that the personal exposures to $\mathrm{PM}_{10}$ of susceptible groups tend to fall in the lower part of the range of exposures found for all volunteers. These two observations suggest that $\mathrm{PM}_{10}$ exposures of the susceptible groups may be lower than those of the population as a whole. When the data were analysed according to their group, it appeared that shadowing very active groups, such as the children, may underestimate their personal exposure, as although the "shadower" is in the vicinity of the child, they may not be as active.

For the pooled data, then, $\mathrm{PM}_{10}$ personal exposures correlate well with microenvironment concentration, and can be modelled once a value for personal cloud contribution is included. As the personal cloud effect is by no means yet fully understood, it is not possible to comment on the significance of this difference. Furthermore, while the immediate source of the personal cloud is reasonably comprehensible, the original source apportionment of the particles contributing to the personal level is not known. It is likely to vary considerably, both between individuals and within individuals over time, but the complexity is such that exploring this route further will prove challenging.

\section{Modelling}

For both $\mathrm{CO}$ and $\mathrm{PM}_{10}$ the modelled concentrations are of an appropriate magnitude, but measured exposures show a far greater range than modelled exposures. This result is most probably a reflection of variability in actual microenvironment concentrations, which the modelling study did not account for as it adopted a single value of concentration for each microenvironment type. Calculated exposures for each group were similar, with very little difference between weekday and 
weekend exposures, except for the young (schoolchildren) for $\mathrm{PM}_{10}$. This is a result of the fact that time spent in the home clearly dominates the activities of the susceptible groups. The influence of smoking in the home is grossly underestimated for $\mathrm{PM}_{10}$.

While this modelling method is able to simulate the general magnitude of a personal exposure measurement, the modelled and measured personal exposure are not well correlated, generally because the modelled personal exposure is unable to reflect the variability of measured personal exposures occasioned by the spread of concentrations within given microenvironments. Thus, the modelled values show a much smaller range than those measured. However, in terms of representing mean exposures, the modelling approach appears valid.

Clearly for carbon monoxide and nitrogen dioxide, if microenvironment data were available from the homes and other environments occupied by susceptible subjects, it would be possible to model their personal exposures reliably. However, the use of generic microenvironment data derived from the pooling of a number of groups leads to a blurring of the genuine differences in personal exposures. Thus, modelled exposures to nitrogen dioxide and carbon monoxide vary little between individuals, while measured five hour personal exposures vary quite substantially. It is clear that for these pollutants modelling can be very representative of true exposures if appropriate microenvironment data are available, but in the absence of such data, the uncertainty of estimates is increased in a manner related to the variability in concentrations within ostensibly similar microenvironments. This conclusion is true also for particles, although the situation is complicated somewhat by the personal cloud effect and the heavy influence of passive smoking on personal exposures, which was not well reflected in our data on static microenvironment concentrations.

When comparing our susceptible groups with healthy subjects, it is clear that for the measured personal exposures, the less active susceptible group individuals, most notably the retired subjects from non-smoking homes, received lower personal exposure doses, especially to particulate matter, than were typical for the healthy adult group. For the schoolchildren, however, their level of activity is extremely high and their school is in a relatively polluted location, and therefore their personal exposures were comparable with, or higher than those of our healthy subjects. The value of the microenvironment modelling approach over estimates of exposure based solely on outdoor monitoring station data is illustrated by the findings of Linaker and colleagues. ${ }^{23}$ In a study of British schoolchildren they found no significant correlation between weekly mean personal exposures to nitrogen dioxide and mean concentrations, measured outdoors only, for the corresponding periods. Dimitroulopoulou and colleagues, ${ }^{24}$ in modelling exposures to nitrogen dioxide, have highlighted the importance of gas cooking as a source of exposure and estimated that the contribution of outdoor exposure to annual mean $\mathrm{NO}_{2}$ exposure is not dominant, varying from $5 \%$ to $24 \%$.

Overall, it is clear that personal activity patterns can strongly influence pollutant personal exposure, and that relatively inactive subjects may well receive lower personal exposures to the air pollutants considered in this study if they spend much of their time inactive within the home.

\section{CONCLUSIONS}

Microenvironment measurements are generally a good surrogate for personal sampling of carbon monoxide, nitrogen dioxide and, with allowance for the personal cloud effect, of $\mathrm{PM}_{10}$. Exceptions to this are situations in which there is considerable separation between personal and static monitors, or where the pollutant concentration exhibits large, short range spatial heterogeneity through, for example, localised sources or removal.
Microenvironment modelling offers an effective means of estimating population exposures to these pollutants without the considerable logistical difficulties of personal sampling. The approach would be improved by determining the range of variability in pollutant concentrations over space and time for key microenvironments, allowing a probabilistic approach to be taken in the use of these models.

Activity pattern has a significant influence on personal exposure. A study of the typical mean and range of activity patterns of susceptible groups would allow further extension of the use of microenvironmental models in probabilistic mode.

Having shown the power of this approach for three key air pollutants, clarification of the uncertainties mentioned could be achieved by further studies of susceptible groups, using larger numbers of individuals and the robust measurement techniques developed during this study. The addition of higher time resolution personal $\mathrm{PM}_{10}$ data would be of value, and this might be achieved through use of the small optical or quartz crystal microbalance instruments that are now available.

\section{ACKNOWLEDGEMENTS}

The authors are pleased to acknowledge funding support of this work by the UK Department of Environment, Transport and the Regions (contract number EPG 1/3/111). They also express thanks to the volunteers who took part in the study.

\section{Authors' affiliations}

\section{R M Harrison, C A Thornton, R G Lawrence, D Mark, R P}

Kinnersley, Division of Environmental Health \& Risk Management, University of Birmingham, Edgbaston, Birmingham B 15 2TT, UK J G Ayres, Department of Research and Development, 1 st Floor, Lincoln House, Birmingham Heartlands Hospital, Bordesley Green East, Birmingham B9 5SS, UK

\section{REFERENCES}

1 Spengler JD, Samet JM. Perspectives on indoor and outdoor air pollution. In: Samet JM, Spengler JD, eds. Indoor air pollution: a health perspective. Baltimore, MD: The John Hopkins University Press, 1991:1-29

2 Crump DR. Volatile organic compounds in indoor Air. Issues Environ Sci Technol 1995;4:109-24.

3 Harrison PTC. Health effects of environmental chemicals. In: Harrison RM, ed. Pollution: cause, effects and control, 3rd edn. Cambridge: Royal School of Chemistry, 1996:418-37.

4 Harrison PTC. Health effects of indoor air pollutants. Issues Environ Sci Technol 1998;10:101-26.

5 Lee HS, Kang B-W, Cheong J-P, et al. Relationships between indoor and outdoor air quality during the summer season in Korea. Atmos Environ 1997:31:1689-93.

6 Thatcher TL, Layton DW. Deposition, resuspension, and penetration of particles within a residence. Atmos Environ 1995;13:1487-97.

7 Leung P-L, Harrison RM. Evaluation of personal exposure to monoaromatic hydrocarbons. Occup Environ Med 1998;55:249-57.

8 Wallace L. Indoor particles: a review. Journal of the Air \& Waste Management Association 1996;46:98-126.

9 World Health Organisation. Environmental health criteria, no.213: carbon monoxide, 2nd edn. International Programme on Chemical Safety, 1999.

10 World Health Organisation. Environmental health criteria, no. 188 nitrogen oxides, 2 nd edn. International Programme on Chemical Safety, 1997.

11 Institute for Environment and Health. Assessment of indoor air quality in the home: executive summary, assessment 2. Leicester: Institute for Environment and Health, 1996.

12 Samet JM. Nitrogen dioxide. In: Samet JM, Spengler JD, eds. Indoor air pollution: a heath perspective. Baltimore, MD: The John Hopkins University Press, 1991:170-87.

13 Jones NC, Thornton CA, Mark D, et al. Indoor/outdoor relationships of particulate matter in domestic homes with roadside, urban and rural locations. Atmos Environ 2000;34:2603-12.

14 Thornton CA, Jones NC, Mark D, et al. Estimation of personal exposure to gaseous and particle pollutants. DETR Research Project 1/5/72, 1999.

15 Leese KE, Cole EC, Hall RM, et al. Measurement of airborne and floor dusts in a nonproblem building. Am Ind Hyg Assoc J 1997;58:432-8.

16 Wang Y, Allen A, Mark D, et al. Development of a personal monitoring method for nitrogen dioxide and sulphur dioxide with Sep-Pak C 18 cartridge sampling and ion chromatographic determination. Journal of Environmental Monitoring 1999;1:423-6. 
17 Mark D, Upton SL, Lyons CP, et al. Personal exposure measurements of the general public to atmospheric particles. Ann Occup Hyg 1997;41:700-6.

18 Wallace L. Recent field studies of personal and indoor exposures to environmental pollutants. Ann N Y Acad Sci 1996:641:7-16.

19 Wallace L. Correlations of personal exposure to particles with outdoor air measurements: a review of recent studies. Aerosol Sci Technol 2000;32:15-25

20 Janssen NAH, Hoek G, Brunekreef B, et al. Personal sampling of particles in adults: relation among personal, indoor and outdoor air concentrations. Am J Epidemiol 1998;147:537-47.

21 Lachenmyer C, Hidy GM. Urban measurements of outdoor-indoor PM $\mathrm{PM}_{2.5}$ concentrations and personal exposure in the deep south. Part I. Pilot study of mass concentrations for nonsmoking subjects. Aerosol Sci Technol 2000;32:34-51.

22 Williams R, Creason J, Zweidinger R, et al. Indoor, outdoor, and personal exposure monitoring of particulate air pollution: the Baltimore elderly epidemiology-exposure pilot study. Atmos Environ 2000;34:4193-204.

23 Linaker $\mathrm{CH}$, Chauhan AJ, Inskip HM, et al. Personal exposures of children to nitrogen dioxide relative to concentrations in outdoor air. Occup Environ Med 2000;57:472-6.

24 Dimitroulopoulou C, Ashmore MR, Byrne MA, et al. Modeling of indoor exposure to nitrogen dioxide in the UK. Atmos Environ 2000;35:269-79.

\section{Manual workers are quitters}

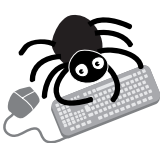

Please visit the Occupational and

Environmental Medicine website [www. occenvmed.com

for link to this

full article.
M anual jobs increase the risk of stopping work, not only in ankylosing spondylitis but also generally, Dutch researchers have discovered. The recent release of employment statistics for the general population in Holland enabled them to extend a previous study of ankylosing spondylitis and employment and compare their data set against data for the general population.

Previously they had shown in a study of 529 patients with ankylosing spondylitis that those with manual jobs had a higher risk of quitting work with disability $(2.3 ; 95 \%$ confidence interval 1.5 to 3.4$)$ than those with a non-manual job, after correction for confounding variables. When now compared with the general population the risk was 4.9 (3.5 to 5.9) for manual workers against 2.2 ( 1.6 to 2.7) for nonmanual workers.

Manual work is therefore a non-specific risk factor for quitting work, conclude the researchers.

A Annals of the Rheumatic Diseases 2002;61:658. 